\title{
Self-Assembled Structures from Solid Cadmium(II) Acetate in Thiol/Ethanol Solutions: A Novel Type of Organic Chemical Garden
}

\author{
Fabrizio Bernini, ${ }^{[a]}$ Elena Castellini, ${ }^{[a]}$ Lorenzo Sebastianelli, ${ }^{* a]}$ Beatrice Bighi, ${ }^{[a]}$ \\ Claro Ignacio Sainz-Díaz, ${ }^{[b]}$ Adele Mucci, ${ }^{[a]}$ Daniele Malferrari, ${ }^{[a]}$ Antonio Ranieri, ${ }^{[c]}$ \\ Maria Franca Brigatti, ${ }^{[a]}$ and Marco Borsari ${ }^{[a]}$
}

Cadmium(II) acetate in tablet form, immersed in ethanol solutions with a high concentration of heptanethiol (30$80 \mathrm{mM}$ ), was able to develop self-assembled sail-shaped structures. The solution in which the self-assembled structure is formed is totally organic (both solute and solvent), thus representing a unique case among organic chemical gardens. The constituting material for this new chemical garden (CG) is made of a single phase, namely a cadmium heptanethiolate with a microcrystalline structure consisting of a central cluster $\left[C d_{n} S_{n}\right]$. The morphological and structural features were studied using different techniques (SEM-EDS, elemental analysis, FT-IR ${ }^{113} \mathrm{Cd}$ MAS NMR, XRPD). A crystalline cell for the $\mathrm{Cd}(\mathrm{II})$ heptanethiolate cluster was obtained that completely differs from that of the solid phase precipitated by mixing an ethanol solution of $\mathrm{Cd}$ (II) acetate with heptanethiol. It follows that the conditions under which the formation of $\mathrm{Cd}$ (II) thiolate occurs (slowly from solid, quickly from solution) play a critical role in determining the nature and structure of the precipitating phase.

\section{Introduction}

A self-assembled structure is produced by a mechanism in which a disordered or only partially ordered system reorganizes itself, without any external driving force, into an organized framework. Dlease check that all author affiliations are correct. $\square$ This is as a result of the spontaneous formation of short-range interactions and specific connections between the pre-existing components. In several cases, self-assembly constitutes an alternative and effective tool for the preparation of atypical structures at meso-, micro- or nanoscale, which require highly technologically demanding processes or are hardly accessible by other assembling techniques. ${ }^{[1]}$ The development of viable procedures for obtaining spontaneous organization of separated components into larger functional units allows, quickly and easily, the achievement of materials and devices with interesting technological features. ${ }^{[2]}$ The term "Chemical garden" (CG) indicates hollow self-assembled structures in form

[a] Dr. F. Bernini, Dr. E. Castellini, Dr. L. Sebastianelli, Dr. B. Bighi,

Prof. A. Mucci, Dr. D. Malferrari, Prof. M. F. Brigatti, Prof. M. Borsari Department of Chemical and Geological Sciences

University of Modena and Reggio Emilia

Via Campi 103, 41125 Modena (Italy)

E-mail: 189633@studenti.unimore.it

[b] Dr. C. Ignacio Sainz-Díaz

Instituto Andaluz de Ciencias de la Tierra (CSIC-UGR)

Av. de las Palmeras, 4, 18100 Armilla, Granada (Spain)

[c] Prof. A. Ranieri

Department of Life Sciences

University of Modena and Reggio Emilia

Via Campi 103, 41125 Modena (Italy)

Supporting information for this article is available on the WWW under https://doi.org/10.1002/syst.202000048

An invited contribution to a Special Collection on Chemobrionics of tubes, balls, sails or more articulated shapes which are produced when a metal salt (other than alkali metals) seed is added in an aqueous solution of silicate, borate, phosphate, carbonate and other anions. ${ }^{[3]}$ The research field concerning the Chemical Gardens is the Chemobrionics due to their biomimetism and because these systems provide confined spaces where prebiotic conditions and reactions can be produced. ${ }^{[4]}$ Investigations on the mechanisms that lead to the formation of different types of CG yield important information on the reactions that underlie the formation of primordial molecules of biological interest. ${ }^{[5]}$ In addition, the study of CG can find applications in several applicative fields: cement setting and hydration, catalysis, metal corrosion, selective carriers for biomolecules and, recently, fabrication of fuel cells to produce energy. ${ }^{[6]}$ The formation and growth of a CG is a tricky mechanism consisting of several steps controlled by physical phenomena such as osmosis, diffusion, membrane permeability, Archimedes' thrust. Processes other than traditional ones have been observed or proposed for the development of CG, but those that potentially find the most interesting applications are the ones involving organic compounds. ${ }^{[7]}$ Presently, only very few cases are known and always involve small organic molecules in aqueous solvent. Overall, $\mathrm{Cd}(\mathrm{II})$ is considered a highly toxic metal ion, being a carcinogen for mammals, an inhibitor of plants growth, and an interferent for photosynthesis and nitrogen metabolism. ${ }^{[8]}$ Nevertheless, a considerable interest has grown towards $\mathrm{Cd}(\mathrm{II})$ thiolate complexes, which is due in part to the ability of these compounds to form diversified [Cd (II) $\mathrm{S}_{\mathrm{m}}$ ] clusters and also zeolitic and/or low-dimensional structures. $\mathrm{Cd}$ (II) forms thiolate complexes with aminoacids with sulphur atoms, like cysteine, taking part of the protein folding process decreasing its toxicity ${ }^{[9]} \mathrm{Cd}(\mathrm{II})$-thiolate interaction has 
found applications in capping cadmium chalcogenides nanoparticles. Some thiolates can be (thermally) decomposed to obtain cadmium sulfide and can be used as precursors for deposition of cadmium sulfide. The nanoparticles/nano-powders of cadmium sulfide show unique physical, chemical and structural properties that are particularly interesting for applications in optoelectronics. ${ }^{[10]}$

Our study will address the following topics: i) production of an organic CG (from organic solvent with organic ligand) without silicate by exploiting the unique $\mathrm{Cd}(\mathrm{II})$-thiol binding properties and investigation of the formation kinetics, morphology and structure of the CG. ii) comprehension of the nature and properties of the obtained Cd thiolate CG, and of possible applications. iii) assess if this procedure leads to the formation of phases different from those obtained with the conventional approach (precipitation from solutions).

\section{Results and Discussion}

\subsection{Growth of the Cd(II) Thiolate as Chemical Garden}

A tablet of each investigated $\mathrm{Cd}(\mathrm{II})$ salt (Anhydrous cadmium acetate $\mathrm{Cd}\left(\mathrm{CH}_{3} \mathrm{COO}\right)_{2}$, cadmium chloride $\mathrm{CdCl}_{2}$, and cadmium sulfate $\mathrm{CdSO}_{4}$ ) was placed in the bottom of a beaker containing $100 \mathrm{ml}$ of heptanethiol (HPT, hereafter) solution at different concentrations $(5-80 \mathrm{mM})$ in ethanol. While the chloride and sulphate tablets did not change over time, the acetate tablets began to widen on the bottom of the container after a few minutes, gaining a gelatinous consistency. After about ten minutes, from the solutions with a HPT concentration between 30 and $80 \mathrm{mM}$ one or more sail-like structures began to develop on the edge of the pad which rapidly grew to yield elevated tower-shaped structures whose upper "sails" constitute the battlements (this structure will be indicated as Cd-CG hereafter). The most pronounced growth is observed, however, at
50 mMHPT concentration (Figure 1a, b; SI FILM 1: timelapse Cd-CG growth; SI 1). In solutions at HPT concentration lower than $30 \mathrm{mM}$, conversely, the tablet decomposed and stretched on the bottom forming a homogeneous layer, until full coverage was reached. No growth of structures was observed (Figure SI 1a). Nevertheless, the ATR-FTIR and XRPD spectra and the elemental analysis of the solid phase obtained at $10 \mathrm{mMHPT}$ are the same as those obtained for the Cd-CG which grows at 50 and $80 \mathrm{mMHPT}$ concentrations (SI 2). This suggests that the heptanethiol concentration affects the growth of the CG but does not play a role on the nature of the formed phase. For this reason, the data and the MAS-NMR measurements presented here refer specifically to the $\mathrm{Cd}-\mathrm{CG}$ grown in $50 \mathrm{mMHPT}$, unless otherwise specified, but the conclusions can be generalized to the other concentrations of HPT.

The grown structures of the $\mathrm{Cd}-\mathrm{CG}$ show a gelatinous consistency and are not very durable. After 24-36 h they collapse depositing fragments on the bottom of the container. The removal of the liquid causes the collapse of the structure, but the fragments, once dried, show a fair consistency. The fact that the Chemical Garden from Cd(II) develops only with acetate as the anion of the $\mathrm{Cd}$ (II) salt suggests that the thiolate can form only in the presence of a base (acetate ion) which acts as an acceptor for the thiol proton. Chloride and sulphate are too weak bases to allow thiol deprotonation.

No significant differences are observed in the morphology of the $\mathrm{Cd}-\mathrm{CG}$ developed between 30 and 80 mMHPT, except that the most consistent growth occurs at $50 \mathrm{mM}$ heptanetiol (see Fig. SI 1b), while at lower and higher concentrations the growths are progressively reduced.

Using a more conventional approach, a Cd(II) heptanethiolate $(\mathrm{Cd}-\mathrm{P})$ was also obtained by precipitation adding an ethanol solution $100 \mathrm{mMHPT}(\mathrm{V}=50 \mathrm{ml})$ to an equimolar ethanol solution of cadmium acetate (still $V=50 \mathrm{ml}$ ) (SI 3). In this case we observe the precipitation of a very fine powder which slowly settles.

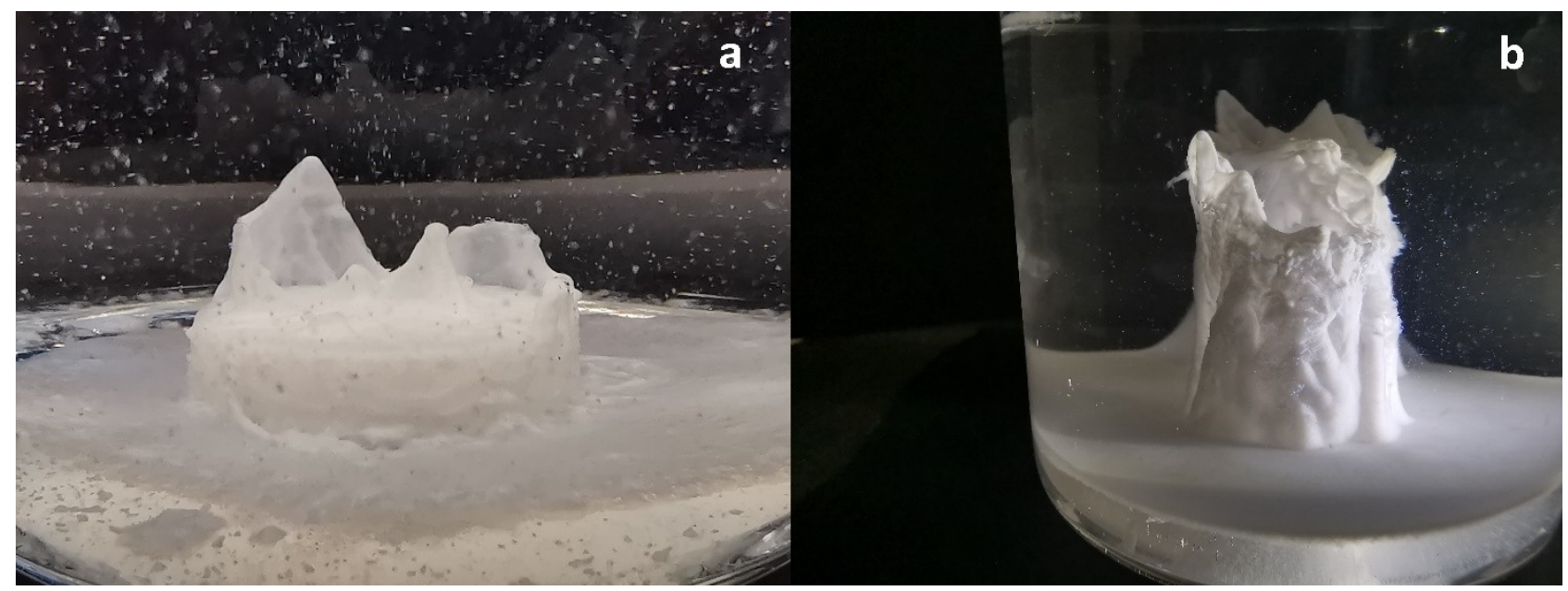

Figure 1. Growth of Cd-CG (starting with a Cd acetate tablet) in an ethanol solution at $50 \mathrm{mM}$ heptanethiol concentration. The process consists of "sails" that grow [(a) growth after $20 \mathrm{~min}$ ] to form a cylindrical structure resembling a tower surmounted by battlements [(b) growth after $1 \mathrm{~h}]$. See also the Supporting Information film: timelapse Cd-CG growth. 


\subsection{Elemental Composition}

The chemical composition of $\mathrm{Cd}-\mathrm{CG}$ and $\mathrm{Cd}-\mathrm{P}$ (both obtained in $50 \mathrm{mMHPT}$ ethanol solution) was determined by elemental analysis $(\mathrm{C}, \mathrm{N}, \mathrm{H}, \mathrm{S})$ and ICP spectroscopy $(\mathrm{Cd}(\mathrm{II}))$. The results are summarized in Table 1. The molar ratios indicate that the $\mathrm{Cd}-\mathrm{CG}$ is mostly formed by a compound of the type $\mathrm{Cd}$ $\left(\mathrm{C}_{7} \mathrm{H}_{15} \mathrm{~S}\right)_{2} \cdot 0.5 \mathrm{H}_{2} \mathrm{O}$. Cd-P shows a similar elemental analysis and, in particular, the same $\mathrm{S} / \mathrm{Cd}$ molar ratio. This suggests that $\mathrm{Cd}(\mathrm{II})$ is bound to 2 thiolate ligands in both cases.

\subsection{SEM Images and EDS Analysis}

The morphology of the "sails" (Figure 1) that constitute the Cd-CG was studied by scanning electron microscopy (SEM) associated with Energy dispersive X-ray spectroscopy (EDS). Samples appear as walls (from 150 to $300 \mu \mathrm{m}$ thick) of denselypacked crystal aggregates (Figure 2a), not visible to the naked eye that can be better observed in the higher SEM magnification.

All crystals show a tabular shape compatible with the monoclinic structural description obtained by X-ray diffraction experiments (see below), and frequently form flower-like aggregates (Figure 2b). Each flower is composed of several crystals arranged radially from the centre. On the external surfaces, crystals with dimension varying from 30-40 $\mu \mathrm{m}$ show thickness often less than $1 \mu \mathrm{m}$ (Figure $2 \mathrm{c}$ ), whereas the crystals that form on the internal surfaces are larger (more than $50 \mu \mathrm{m}$ ) and thicker $(2-3 \mu \mathrm{m})$ (Figure $2 \mathrm{~d}$ ). The EDS spectrum (Figure 2e) demonstrates that the $\mathrm{Cd}-\mathrm{CG}$ compound consists of $\mathrm{S}$ and $\mathrm{Cd}$ ( $C$ is also observed, but is partially due to the procedure of sample preparation which involves metallisation by carbon coating, SI 3), according with the presence of a $\mathrm{Cd}(\mathrm{II})$ thiolate.

The Cd-P crystals (Figure 3) appear completely different with respect to $\mathrm{Cd}-\mathrm{CG}$ crystals. They assume a rounded shape with surface dimensions less than $1 \mu \mathrm{m}$ and thickness of about $0.1 \mu \mathrm{m}$. As observed for Cd-CG crystals, the EDS spectrum shows only $\mathrm{Cd}$ and $\mathrm{S}$.

\subsection{NMR Spectra}

${ }^{113} \mathrm{Cd},{ }^{1} \mathrm{H}$ and ${ }^{13} \mathrm{C}$ NMR measurements were performed on the crystalline material forming the $\mathrm{Cd}-\mathrm{CG}$ (Figure 4 and SI 4). Two ${ }^{113} \mathrm{Cd}$ signals were detected in the pulse-and-acquired MAS NMR spectrum with chemical shifts slightly dependent on the MAS rate and hence on temperature. Deconvolution of the two signals demonstrates similar areas thus suggesting the presence of two equally occupied sites of $\mathrm{Cd}(\mathrm{II})$ in the crystal structure of the material forming $\mathrm{Cd}-\mathrm{CG}$ (Figure 4). The chemical shifts are close to those reported for cadmium tetrahedrally coordinated to four thiolate ligands (either terminal or bridging), such as the $\mathrm{CdS}_{4}$ sites of the decanuclear $\left[\mathrm{Cd}_{10}\left(\mathrm{SCH}_{2} \mathrm{CH}_{2} \mathrm{OH}\right)_{6}\right]\left(\mathrm{ClO}_{4}\right)_{4} \cdot 8 \mathrm{H}_{2} \mathrm{O}$ $\left(\delta_{\text {iso }}=650\right.$ and $\left.667 \mathrm{ppm}\right)$ complex ${ }^{[11]}$ or cadmium in polynuclear $\left[\mathrm{Cd}\left(\mathrm{SC}_{5} \mathrm{H}_{9} \mathrm{NHMe}\right)_{2}\right]\left(\mathrm{ClO}_{4}\right)_{2} \quad\left(\delta_{\text {iso }}=641 \mathrm{ppm}\right), \quad$ dinuclear $\left[\mathrm{Et}_{4} \mathrm{~N}\right]_{2}\left[\mathrm{Cd}_{2}\left(\mathrm{SC}_{6} \mathrm{H}_{11}\right)_{6}\right]\left(\delta_{\text {iso }}=610 \mathrm{ppm}\right)^{[12]}$ and other more complex systems. ${ }^{[13]}$ The ${ }^{113} \mathrm{Cd}$ NMR spectra, therefore, indicate the presence of two (magnetically different) cadmium sites tetrahedrally coordinated to four thiolates. These two cadmium centers could be (structurally) nearly equivalent to each other, but belonging to centres with slightly different distorted tetrahedral symmetry.

The presence of alkyl chain conformers can also be inferred by ${ }^{13} \mathrm{C}$ NMR spectrum (SI 4, Figure SI 4a) in which multiple signals for the alkyl carbons are detected. It is well known, especially from studies on polymers in the solid state, that carbon signals in gauche conformers are shielded, with respect to those in the all-trans one, due to a g-gauche effect. ${ }^{[14]}$

\subsection{ATR-FTIR Spectra}

The IR spectrum of Cd-CG crystals is compared with those of $\mathrm{Cd}$ (II) acetate, heptanethiol and precipitated Cd-P (Figure 5). The IR spectrum of $\mathrm{Cd}-\mathrm{CG}$ resembles that of heptanethiol. In the region just below $3000 \mathrm{~cm}^{-1}$, strong bands due to the asymmetric and symmetric stretching vibrations of $\mathrm{CH}_{3}$ (at 2956 and $2872 \mathrm{~cm}^{-1}$, respectively) and $\mathrm{CH}_{2}$ (at 2920 and $2850 \mathrm{~cm}^{-1}$, respectively) of the aliphatic chain of heptanethiol were observed ${ }^{[15]}$ They resulted similar to those of Cd-P $(2955,2872$, 2920, $\left.2850 \mathrm{~cm}^{-1}\right)$, but somewhat different from those of heptanethiol (bands at 2955, 2871, 2924, $2853 \mathrm{~cm}^{-1}$ ), according to the involvement of deprotonated thiol in the coordination to Cd(II). Bands due to S-H stretching $\left(2550-2600 \mathrm{~cm}^{-1}\right)$ were not observed $^{[16]}$ in $\mathrm{Cd}-\mathrm{CG}$ spectrum indicating that the thiol interacts with $\mathrm{Cd}(\mathrm{II})$ only in deprotonated form. ${ }^{[17]}$ The $v(\mathrm{C}-\mathrm{S})$ stretching vibrations give rise to two intense bands at 721 and $647 \mathrm{~cm}^{-1},{ }^{[16]}$ due to different conformers ( $T$ and $\mathrm{GT}$, respectively). ${ }^{[18]}$ These vibrations were observed also for heptanethiol (724 and $655 \mathrm{~cm}^{-1}$ ) and for Cd-P (722 and $645 \mathrm{~cm}^{-1}$ ). The band observed at $1550 \mathrm{~cm}^{-1}$ in $\mathrm{Cd}-\mathrm{CG}$ can be assigned to the presence of hydration or crystallization water. Other bands related to $\mathrm{Cd}-\mathrm{CG}$ were: i) $\delta\left(\mathrm{CH}_{2}\right)$ (scissoring motion of alkyl chain) and $\delta\left(\mathrm{CH}_{3}\right)$ bending deformations at 1465 and $1460 \mathrm{~cm}^{-1}$, respectively $\left(1466\right.$ and $1458 \mathrm{~cm}^{-1}$ for heptanethiol and 1466 and $1457 \mathrm{~cm}^{-1}$ for $\left.\mathrm{Cd}-\mathrm{P}\right)$; ii) $\mathrm{CH}_{3}$ symmetric deformation at $1376 \mathrm{~cm}^{-1}\left(1378 \mathrm{~cm}^{-1}\right.$ for heptanethiol and $1377 \mathrm{~cm}^{-1}$

Table 1. Elemental analysis, expressed as $\mathrm{w} / \mathrm{w} \%$, of $\mathrm{Cd}-\mathrm{CG}$ and $\mathrm{Cd}-\mathrm{P}$. The last two columns show the $\mathrm{S} / \mathrm{Cd}$ and $\mathrm{C} / \mathrm{S}$ molar ratios obtained by conversion of the mass of the element into the corresponding number of moles. The data refer to the $\mathrm{Cd}-\mathrm{CG}$ and $\mathrm{Cd}-\mathrm{P}$ obtained in an ethanol solution at $50 \mathrm{mM}$ heptanethiol concentration.

\begin{tabular}{|llllllll} 
& $\mathrm{N}[\%]$ & $\mathrm{C}[\%]$ & $\mathrm{H}[\%]$ & $\mathrm{S}[\%]$ & $\mathrm{Cd}[\%]$ & S/Cd molar ratio & C/S molar ratio \\
\hline Cd-CG & 0 & 43.6 & 8.2 & 16.4 & 28.3 & 2.03 & 7.09 \\
Cd-P & 0 & 42.7 & 7.9 & 15.5 & 27.9 & 1.95 & 7.34 \\
\hline
\end{tabular}



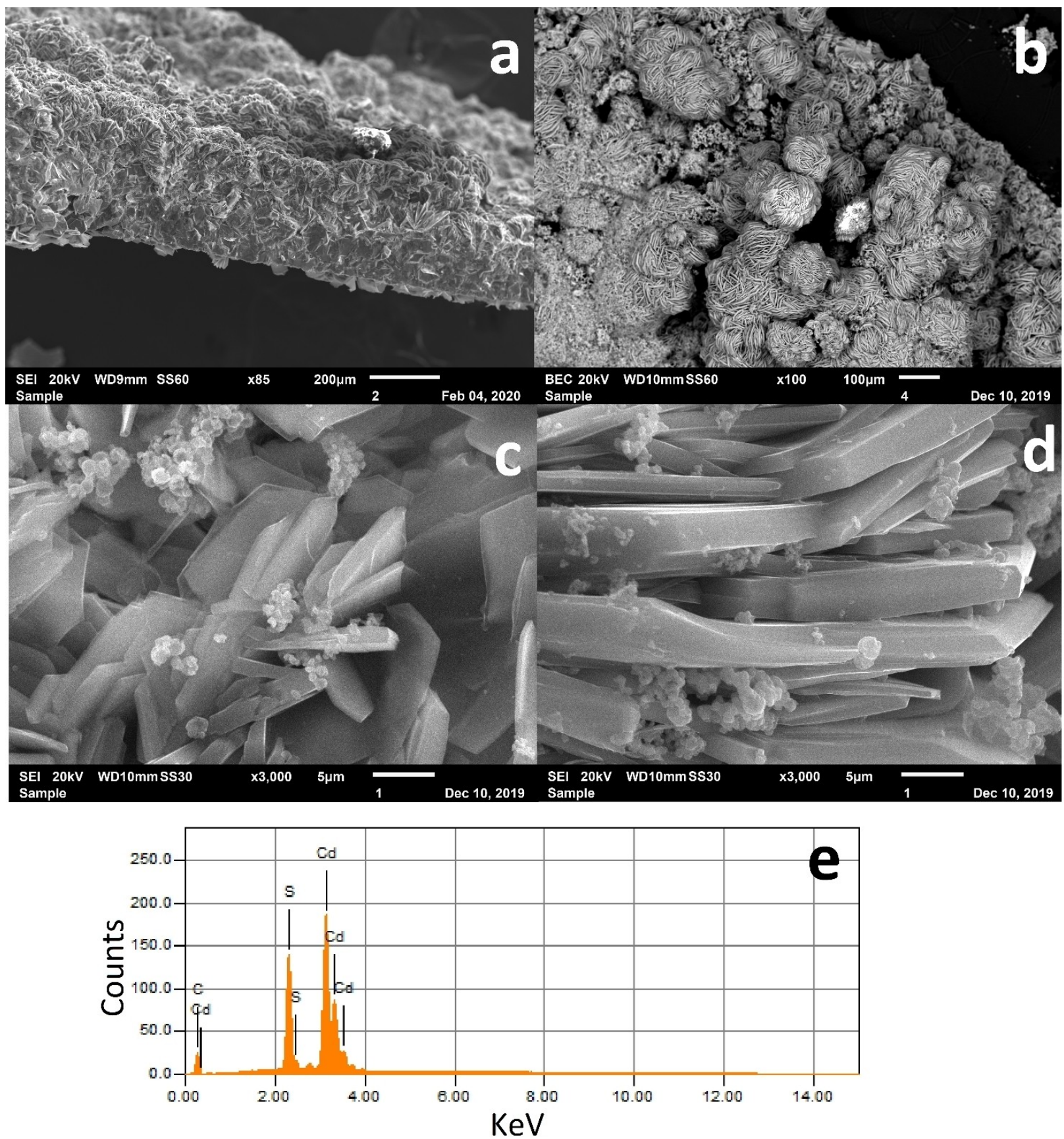

Figure 2. a) Scanning electron microscopy (SEM) images of a Cd-CG "sail". b) Arrangement of crystals on the "sail" internal surfaces to form flower-like aggregates; c) Crystals on external surfaces; d) Crystals on internal surfaces; e) EDS spectrum of Cd-CG. The images show the Cd-CG grown in an ethanol solution at $50 \mathrm{mM}$ heptanethiol concentration.

for ( $d-P)$ iii) scissoring of the methylene group adjacent to the $C d-S$ bond ${ }^{[18]}$ at $1420 \mathrm{~cm}^{-1}\left(1429 \mathrm{~cm}^{-1}\right.$ for $C d-P$, the corresponding scissoring of heptanethiol for the methylene group adjacent to the $\mathrm{H}-\mathrm{S}$ bond is observed at $\left.1435 \mathrm{~cm}^{-1}\right){ }^{[19]}$ No signal due to $\mathrm{Cd}(\mathrm{II})$ acetate was detected. The differences observed in the IR spectra of $C d-C G$ and $C d-P$, in particular those of the scissoring of the methylene group adjacent to the $\mathrm{Cd}-\mathrm{S}$ bond, suggest appreciable differences in the arrangement of the thiolate alkyl chains.
It is worth noting that the ATR-FTIR and XRPD spectra and the elemental analysis of the homogeneous layer formed on the bottom of the beaker when heptanethiol concentration is lower than $30 \mathrm{mM}$ (SI 2) are the same as those obtained for the $\mathrm{Cd}-\mathrm{CG}$ which grows at higher heptanethiol concentrations. This suggests, therefore, that the heptanethiol concentration affects only the growth of the $C G$, without playing a role on the chemical and crystalline nature of the formed material. 

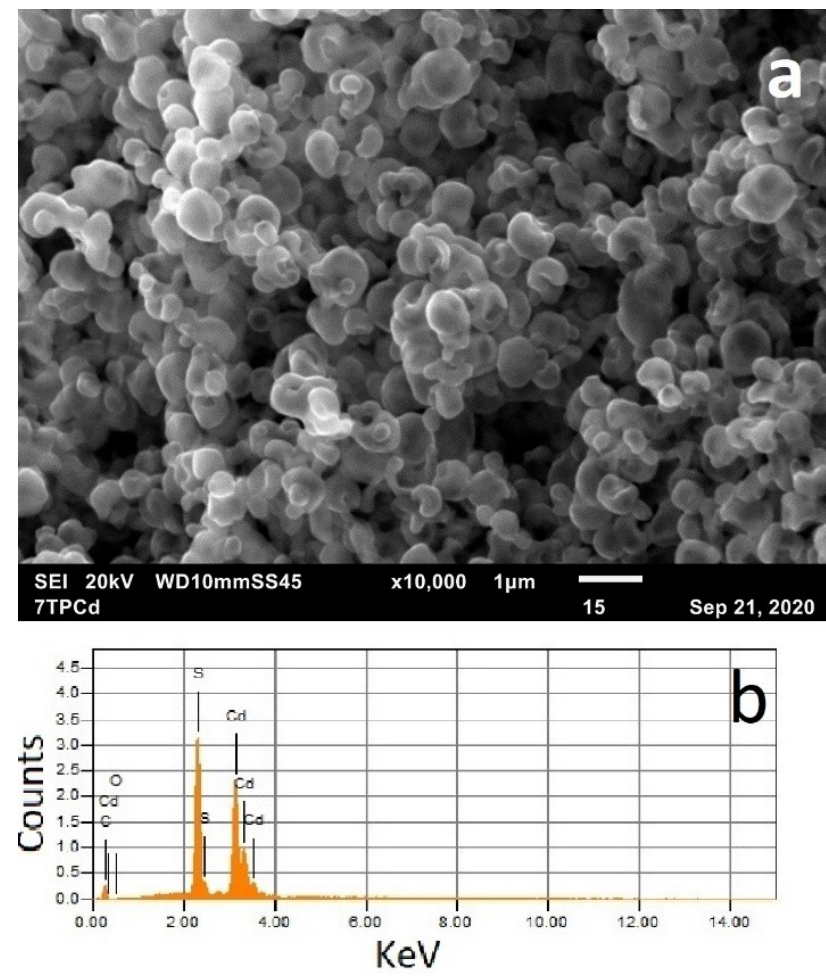

Figure 3. a) Scanning electron microscopy (SEM) images of Cd-P crystals; b) EDS spectrum of $\mathrm{Cd}-\mathrm{P}$. The data refer to the $\mathrm{Cd}-\mathrm{P}$ precipitated by an ethanol solution at $50 \mathrm{mM}$ heptanethiol concentration.

\subsection{XRPD Analysis}

The powder X-ray diffraction spectrum for Cd-CG is reported in Figure 6. This spectrum differs from literature data referring to other thiolate complexes of $\mathrm{Cd}(\mathrm{II})$ and from the calculated spectra that we derived from structural data reported for these complexes. Unfortunately, small size, brittleness and crystal twinning prevented single crystal X-ray determination. Some structural data, such as cell parameters, were obtained from XRPD spectrum using well established procedures. ${ }^{[20]}$ Unit cell parameters obtained by introducing $d$ values of 37 peaks $(a=$ $\left.16.421(1) \AA, b=14.549(1) \AA, c=10.377(1) \AA, \beta=96.553(7)^{\circ}\right)$ indicate a monoclinic cell, common to other thiolate complexes of $\mathrm{Cd}(\mathrm{II})^{[21]}$ and yield a cell volume of $2463.1(2) \AA^{3}$. The resulting cell volume is similar to other metal(II) thiolates complexes. ${ }^{[21]}$ Assuming that the $\mathrm{Cd}(\mathrm{II})$ thiolate consists of a $\left[\mathrm{Cd}_{4} \mathrm{~S}_{4}\right]$ cluster, the proposed crystalline cell is consistent with the presence of two molecules of $\mathrm{Cd}(\mathrm{II})$ thiolate for unit cell.

The solid compound directly obtained by mixing ethanol solutions of $\mathrm{Cd}(\mathrm{II})$ acetate and heptanethiol (Cd-P) shows a XRPD tracing clearly different from that observed for Cd-CG (Figure 6). In addition, it consists of defined peaks at low $2 \theta$ values and broad bands at higher $\theta$ values, thus suggesting an increase in amorphous content. These facts indicate that the two solids correspond to two different phases with different XRD tracing and, probably, assembly.

\section{Conclusions}

The organic Chemical Garden obtained from $\mathrm{Cd}(\mathrm{II})$ and heptanethiol shows distinctive characteristics compared to

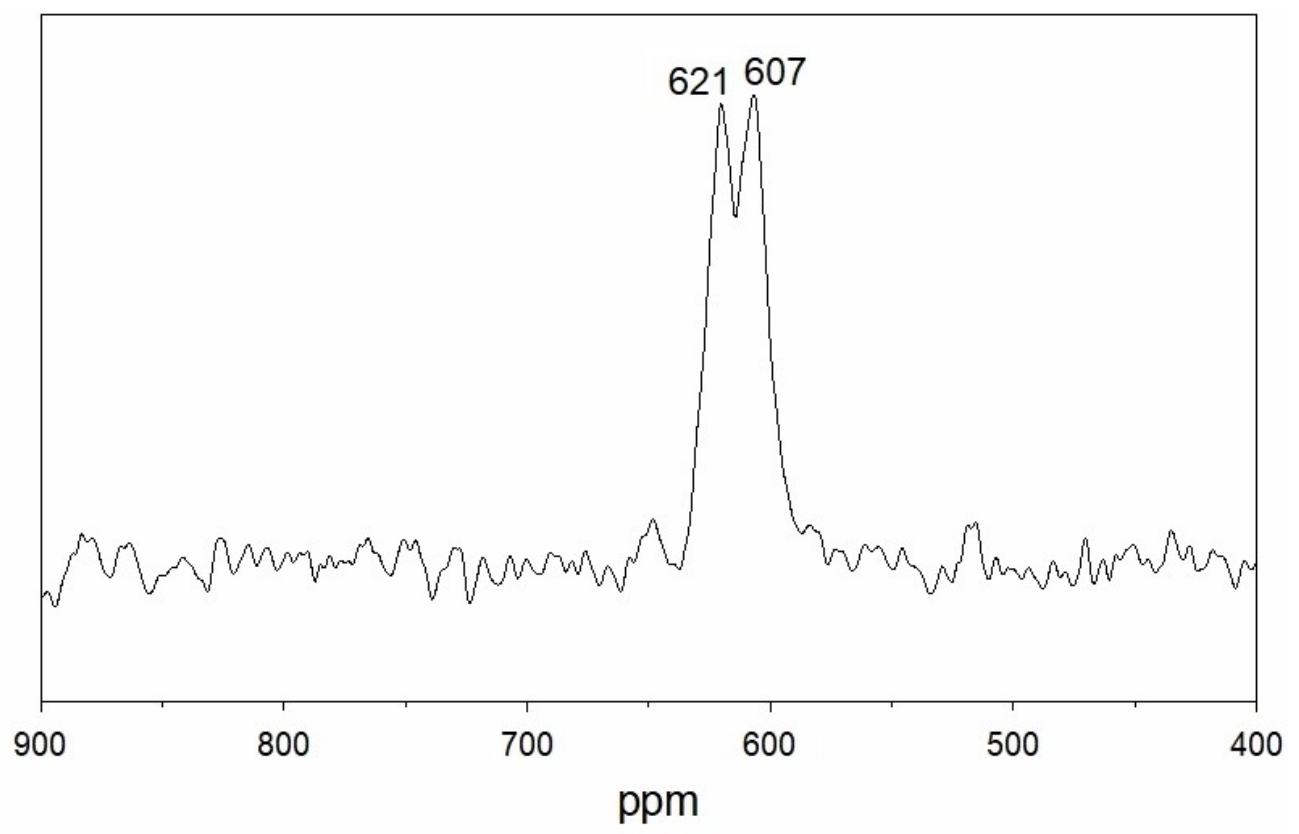

Figure 4. ${ }^{113} \mathrm{Cd}$ MAS NMR spectrum of $\mathrm{Cd}-\mathrm{CG}$ acquired at $33 \mathrm{kHz}$ MAS rate with a pulse-and-acquire sequence. The spectrum refers to the Cd-CG grown in an ethanol solution at $50 \mathrm{mM}$ heptanethiol concentration. 

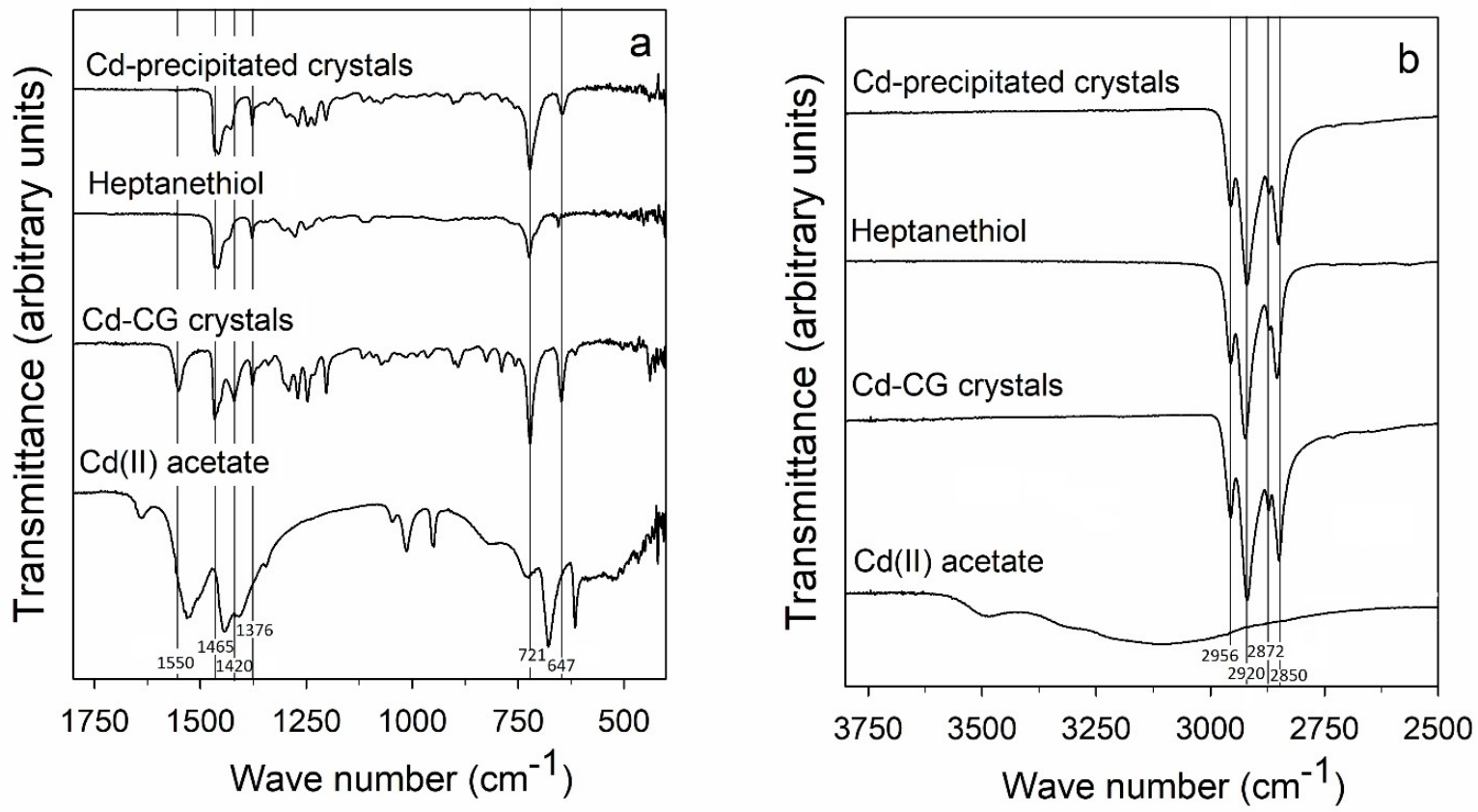

Figure 5. TR-FTIR spectra of: $\mathrm{Cd}(\mathrm{II})$ acetate, $\mathrm{Cd}-\mathrm{CG}$ (grown in an ethanol solution at $50 \mathrm{mM}$ heptanethiol concentration), heptanethiol and Cd-P (precipitated by an ethanol solution at $50 \mathrm{mM}$ heptanethiol concentration). Wavenumber range: a) $1750-500 \mathrm{~cm}^{-1}$; b) $3750-2500 \mathrm{~cm}^{-1}$.

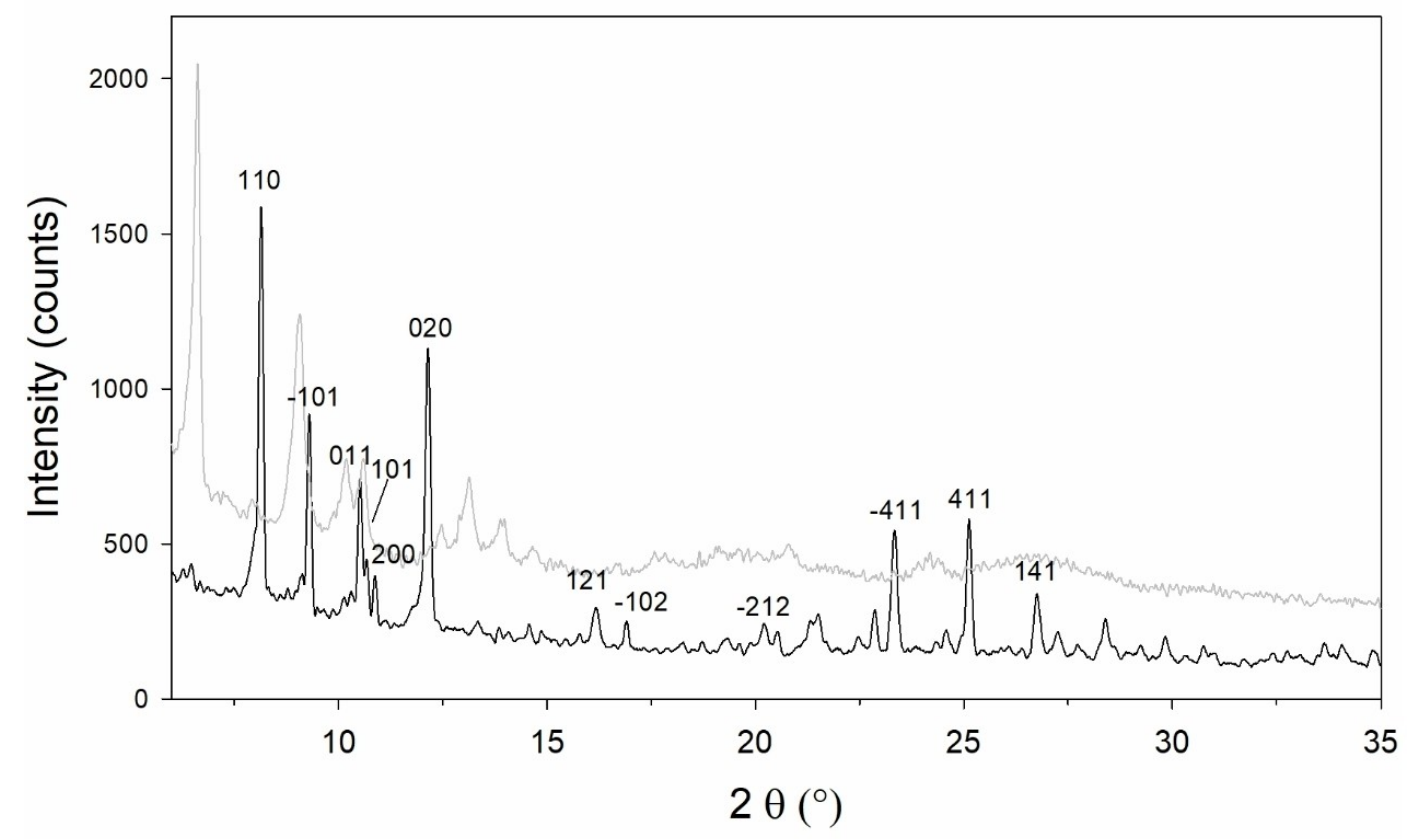

Figure 6. X-ray diffraction patterns of Cd-CG (black line) and Cd-P (grey line). Indices of some diffraction peak referred only to the Cd-CG sample are reported, details in the Supporting Information (SI5). The spectra refer to the $\mathrm{Cd}-\mathrm{CG}$ and $\mathrm{Cd}-\mathrm{P}$ obtained in an ethanol solution at $50 \mathrm{mM}$ heptanethiol concentration.

previously reported Chemical Gardens in terms of solid phase, development mode and assembly. Unlike silica Chemical Gardens, which often contain significant amounts of amorphous phases, the membrane forming the Cd-CG consists of well- developed crystals closely packed and shows well-defined peaks in the XRD spectrum. In this respect, the behavior of $\mathrm{Cd}-\mathrm{CG}$ resembles that of chemical gardens grown in aqueous solutions of phosphate or carbonate, even without silicate, 
where the presence of a relevant number of crystalline phases is observed together with eventual amorphous/poorly crystalline phases. ${ }^{[22]}$ Unlike the latter, however, the Cd-CG is formed by a single crystalline solid phase, a $\mathrm{Cd}$ (II) thiolate, and exhibits poor mechanical stability, collapsing within 24-36 h. The growth process of the $\mathrm{Cd}-\mathrm{CG}$ strongly affects the nature of the solid phase, yielding a crystalline phase different from that obtained by direct precipitation.

Cadmium thiolate complexes deserve particular attention because of the plethora of diversified structures that they can adopt and their potential use as precursors for semiconductors or optical materials, and as models for metalloproteins. Since properties and possible applications of these compounds are strongly conditioned by the structure, crystalline phase and state of dispersion, the extension of their use in optics, gas separation, spectroscopy, catalysis and nano materials would greatly benefit from the development of new procedures aimed at differentiating the type and structure of the synthesized compounds.

\section{Experimental Section}

Experimental details can be found in the Supporting Information.

\section{Acknowledgements}

The Authors would like to acknowledge the contribution of the COST Action CA17120 supported by the EU Framework Programme Horizon 2020. This research is also under the contribution of PRIN2017 "Mineral Reactivity, a Key to Understand Large-Scale Processes: from Rock Forming Environments to Solid Waste Recovering/Lithification" - Project Code 2017L83S77.

\section{Conflict of Interest}

The authors declare no conflict of interest.

Keywords: biomimetic structures - cadmium - chemical gardens · crystalline membranes $\cdot$ self-assembly

[1] E. Nakouzi, O. Steinbock, Sci. Adv. 2016, 2, e1601144.

[2] M. Kellermeier, F. Glaab, E. Melero-García, J. M. García-Ruiz in Methods in Enzymology, Vol 532 (Ed.: J. J. De Yoreo), Academic Press: Cambridge, MA, USA, 2013, pp. 225-256

[3] L. M. Barge, S. S. S. Cardoso, J. H. E. Cartwright, G. J. T. Cooper, L. Cronin, A. De Wit, I. J. Doloboff, B. Escribano, R. E. Goldstein, F. Haudin, D. E. H. Jones, A. L. Mackay, J. Maselko, J. J. Pagano, J. Pantaleone, M. J. Russell, C. I. Sainz-Díaz, O. Steinbock, D. A. Stone, Y. Tanimoto, N. L. Thomas, Chem. Rev. 2015 115, 8652-8703.
[4] a) S. S. S. Cardoso, J. H. E. Cartwright, J. Čejková, L. Cronin, A. De Wit, S Giannerini, D. Horváth, A. Rodrigues, M. J. Russell, C. I. Sainz-Díaz, Á. Tóth, Artificial Life 2020, 20, 315-326; b) S. Leduc, The Mechanism of Life, Rebman Company, New York, 1911.

[5] a) M. Getenet, J.M. García-Ruiz, C. Verdugo-Escamilla, I. GuerraTschuschke, Crystals 2020, 10, 467-477; b) S. McMahon, Proc. R. Soc. $B$ 2019, 286, 20192410.

[6] L. M. Barge, Y. Abedian, M. J. Russell, I. J. Doloboff, J. H. Cartwright, R. D. Kidd, I. Kanik, Angew. Chem. Int. Ed. 2015, 54, 8184-8187; Angew. Chem. 2015, 127, 8302-8305.

[7] M. R. Hooks, P. Webster, J. M. Weber, S. Perl, L. M. Barge, Langmuir 2020, 36, 5793-5801.

[8] a) M. L. Sall, A. K. D. Diaw, D. Gningue-Sall, S. E. Aaron, J-J. Aaron, Environ. Sci. Pollut. Res. 2020, 27, 29927-29942; b) G. Genchi, M. S. Sinicropi, G. Lauria, A. Carocci, A. Catalano, Int. J. Environ. Res. Public Health 2020, 17, 3782.

[9] F. Jalilehvand, B. O. Leung, V. Mah, Inorg. Chem. 2009, 48, 5758-5771.

[10] N. V. Hullavarad, S. S. Hullavarad, P. C. Karulkar, J. Nanosci. Nanotechnol. 2008, 8, 3272-3299.

[11] S. Lacelle, W. C. Stevens, D. M. Kurtz Jr., J.W. Richardson Jr., R. A. Jacobson, Inorg. Chem. 1984, 23, 930-935.

[12] J. Sola, P. Gonzalez-Duarte, J. Sanz, I. Casals, T. Alsina, I. Sobrados, A Alvarez-Larena, J.-F. Piniella, X. Solans, J. Am. Chem. Soc. 1993, 115, 10018-10028.

[13] C. You, E. A. Mackay, P. M. Gehrig, P. E. Hunziker, J. H. R. Kaègi, Arch. Biochem. Biophys. 1999, 372, 44-52.

[14] K. Saalwächter, H.W. Spiess, in Polymer Science: A Comprehensive Reference, Vol. 2, (Eds.: M. Moeller, K. Matyjaszewski) Elsevier, 2012, pp.185-219.

[15] a) L. Bertilsson, B. Liedberg, Langmuir 1993, 9, 141-149; b) M. Himmelhaus, F. Eisert, M. Buck, M. Grunze, J. Phys. Chem. B 2000, 104 576-584; c) T. M. Uehara, H. B. de Aguiar, K. Bergamaski, P. B. Miranda, J. Phys. Chem. C 2014, 118, 20374-20382.

[16] a) J. Coates in Encyclopedia of Analytical Chemistry (Ed.: R. A. Meyers), John Wiley \& Sons Ltd, Chichester, 2000, pp. 10815-10837; b) O.P. Yablonskii, N. M. Rodionova, L. F. J. Lapuka, Appl. Spectrosc. 1973, 19, 1303-1305

[17] a) F. Bernini, E. Castellini, D. Malferrari, G. R. Castro, C. I. Sainz-Díaz, M. F. Brigatti, M. Borsari, ACS Appl. Mater. Interfaces 2017, 9, 1045-1056; b) E. Castellini, D. Malferrari, F. Bernini, A. Mucci, M. Borsari, M. F. Brigatti, Microporous Mesoporous Mater. 2019, 285, 150-160; c) E. Castellini, D. Malferrari, F. Bernini, B. Bighi, A. Mucci, C. I. Sainz-Díaz, A. Serrano, G. R. Castro, M. F. Brigatti, M. Borsari, Appl. Clay Sci. 2020, 192, 105642.

[18] M. J. Hostetler, J. J. Stokes, R. W. Murray, Langmuir 1996, 12, 3604-3612.

[19] M. Hayashi, Y. Shiro, H. Murata, Bull. Chem. Soc. Jpn. 1966, 39, 112-117.

[20] T. J. B. Holland, S. A. T. Redfern, Min. Mag. 1997, 61, 65-77.

[21] a) A. D. Watson, Ch. Pulla Rao, J. R. Dorfman, R. H. Holm, Inorg. Chem 1985, 24, 2820-2826; b) S. Lacelle, W. C. Stevens, D. M. Kurtz Jr., J. W. Richardson Jr., R. A. Jacobson, Inorg. Chem. 1984, 23, 930-935; c) S. Bakbak, C. D. Incarvito, A. L. Rheingold, D. Rabinovich, Inorg. Chem. 2002, 41, 998-1001.

[22] a) E. Rauscher, G. Schuszter, B. Bohner, Á. Tóth, D. Horváth, Phys. Chem. Chem. Phys. 2018, 20, 5766-5770; b) Á. Tóth, D. Horváth, R. Smith, J. R. McMahan, J. Maselko, J. Phys. Chem. C 2007, 111, 14762-14767; c) E. Nakouzi, P. Knoll, K. B. Hendrix, O. Steinbock, Phys. Chem. Chem. Phys. 2016, 119, 23044-23052; d) B. Bohner, G. Schuszter, O. Berkesi, D. Horváth, Á. Tóth, Chem. Commun. 2014, 50, 4289-4291; e) B. Bohner, G. Schuszter, D. Horváth, Á. Tóth, Chem. Phys. Lett. 2015, 631-632, 114117; f) E. Tóth-Szeles, G. Schuszter, Á. Tóth, Z. Kónya, D. Horváth, CrystEngComm 2016, 18, 2057-2064; g) E. A. B. Hughes, R. L. Williams, S. C. Cox, L. M. Grover Langmuir 2017, 33, 2059-2067; h) S. S. S. Cardoso, J. H. E. Cartwright, C. I. Sainz-Díaz, Icarus 2019, 319, 337-348.

Manuscript received: October 16, 2020

Accepted manuscript online: December 2, 2020

Version of record online: 


\section{ARTICLES}

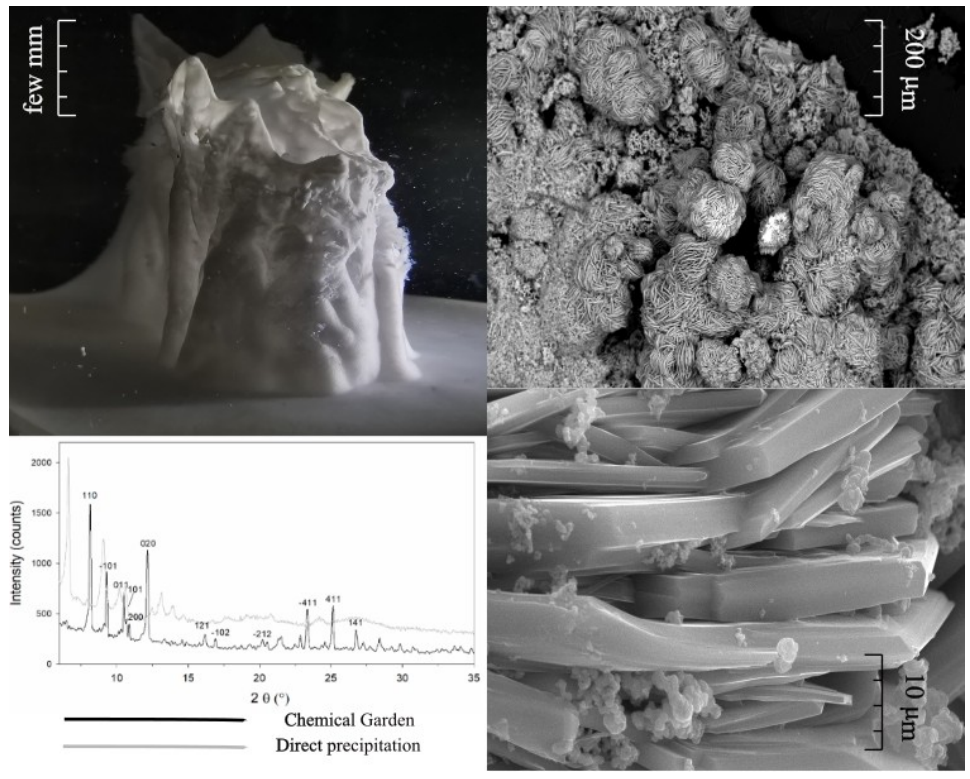

Dr. F. Bernini, Dr. E. Castellini, Dr. L. Sebastianelli*, Dr. B. Bighi, Dr. C. Ignacio Sainz-Díaz, Prof. A. Mucci, Dr. D. Malferrari, Prof. A. Ranieri, Prof. M. F. Brigatti, Prof. M. Borsari

$1-9$

Self-Assembled Structures from Solid Cadmium(II) Acetate in Thiol/Ethanol Solutions: A Novel Type of Organic Chemical Garden

Organic chemical garden - a

challenge: Cadmium acetate and heptanethiol combined give an intriguing chemical garden which grows in organic solvent without silicate. The resulting framework is made of densely packed crystals, whose structure is different from that precipitated by mixing ethanol solutions of cadmium acetate and heptanethiol.

\section{\#\# SPACE RESERVED FOR IMAGE AND LINK}

Share your work on social media! ChemSystemsChem has added Twitter as a means to promote your article. Twitter is an online microblogging service that enables its users to send and read short messages and media, known as tweets. Please check the pre-written tweet in the galley proofs for accuracy. If you, your team, or institution have a Twitter account, please include its handle @username. Please use hashtags only for the most important keywords, such as \#catalysis, \#nanoparticles, or \#proteindesign. The ToC picture and a link to your article will be added automatically, so the tweet text must not exceed 250 characters. This tweet will be posted on the journal's Twitter account (follow us @ ChemSystemsChem) upon publication of your article in its final (possibly unpaginated) form. We recommend you to re-tweet it to alert more researchers about your publication, or to point it out to your institution's social media team.

\section{ORCID (Open Researcher and Contributor ID)}

Please check that the ORCID identifiers listed below are correct. We encourage all authors to provide an ORCID identifier for each coauthor. ORCID is a registry that provides researchers with a unique digital identifier. Some funding agencies recommend or even require the inclusion of ORCID IDs in all published articles, and authors should consult their funding agency guidelines for details. Registration is easy and free; for further information, see http://orcid.org/.

Dr. Fabrizio Bernini

Dr. Elena Castellini

Dr. Lorenzo Sebastianelli http://orcid.org/0000-0001-5242-6335

Dr. Beatrice Bighi

Dr. Claro Ignacio Sainz-Díaz

Prof. Adele Mucci

Dr. Daniele Malferrari 
Prof. Antonio Ranieri

Prof. Maria Franca Brigatti

Prof. Marco Borsari 